\title{
Assessment of the environmental determinants of public health and their impact on the regional economy
}

\author{
Anna Pepelyaeva ${ }^{1, *}$, and Yuliya Karpovich ${ }^{1}$ \\ ${ }^{1}$ Perm National Research Polytechnic University, Department of Economics and Finance, 614990, 29 \\ Komsomolsky ave., Perm, Russia
}

\begin{abstract}
At present, the significance of the ecological component in the socio-economic development of the regions has grown significantly. Sustainable socio-economic development of the region is possible only with the improvement of the regional ecosystem and ensuring environmental security. The article proposes a methodology for assessing regional environmental factors and their impact on the health of the inhabitants of the territory, as well as assessing the impact of public health on the quality and standard of living of the population (GRP is used as a criterion for assessing the standard of living of the population in the region, and HDI is used as a criterion assessing quality of life in the region). Approbation of the methodology was carried out on the example of seven subjects of the Russian Federation (Perm region, Nizhny Novgorod region, Sverdlovsk, Samara and Chelyabinsk regions, Tatarstan and Bashkortostan Republics). All regions demonstrate a low level of functioning of the ecological component, in addition, three regions (Perm region, the Republic of Bashkortostan and the Sverdlovsk region) show negative dynamics. The regression analysis presented in the article showed a significant influence of the ecological component on the health status of the inhabitants of all the assessed regions. The proposed methodology can be applied not only for interregional, but also for intercountry analysis of environmental conditions. The development and implementation of measures to reduce the dysfunctions of the ecological component of the regional socio-economic system will mitigate the negative impact on the regional economy, improve the quality of life of the population of the regions.
\end{abstract}

The economic system at the present stage of development is considered as a system of a technogenic type with its inherent over-exploitation of natural resources exceeding the possibilities of their natural reproduction, which results in a shortage of food, an increase in morbidity (including genetic and immune diseases), increased drug consumption, etc. [1, p. $452,454]$. According to researchers, at the beginning of the 20th century, the possibilities of the ecosystem to cope with the consequences of human economic activity were exceeded by $25-30 \%$, and the ecological debt of mankind was estimated at 4 trillion dollars [2, p.

* Corresponding author: a.v.pepelyaeva@ mail.ru 
208]. In our country, environmental problems become more serious: in 2017 Russia was one of the four countries in the world in terms of carbon dioxide intensity (Enerdata, 2017), $15 \%$ of the territory of the country falls on the zones of ecological catastrophe $[3 ; 2, \mathrm{p}$. $211]$.

Evaluation of extremely negative results of the developed technogenic type of economic development led to the development of concepts of world development, taking into account environmental factors: the "green economy", theories of ecological modernization (J. Huber, A. Mol, M. Jonik, etc.) [1, p. 455, 456].

The urgency of environmentally oriented development of Russian regional socioeconomic systems is due to the general inefficiency of the use of natural resources, inadequate energy saving, medical and demographic problems, and the poor quality of the regulatory and legal base in this area.

In our opinion, the impact of improving the environmental living conditions in the region is to reduce the damage to the regional ecosystem and improve the medical and demographic situation in the region, which in turn will lead to higher labor productivity, an increase in the HDI and GRP.

The proposed author's methodology for assessing the impact of environmental determinants of public health on the economy of the region includes several stages.

The first stage is the selection of indicators that characterize the environmental determinants that affect the health of the inhabitants of the region (Table 1).

Table 1. Indicators assessing environmental conditions in the region.

\begin{tabular}{|l|l|}
\hline$X_{I}$ & Volume of circulating and consecutively used water, cubic meters per capita \\
\hline $\boldsymbol{X}_{2}$ & Discharge of contaminated sewage into surface water bodies, cubic meters per capita \\
\hline $\boldsymbol{X}_{3}$ & Emissions of pollutants into the atmosphere from stationary sources, tons per capita \\
\hline $\boldsymbol{X}_{4}$ & Capture of atmospheric pollutants from stationary sources, tons per capita \\
\hline $\boldsymbol{X}_{5}$ & Use of fresh water, cubic meters per capita \\
\hline $\bar{E} \overline{\boldsymbol{I}}$ & Integral indicator of the ecological component of the regional socio-economic system \\
\hline Environmental indicators - environmental indicators of the regional socio-economic system
\end{tabular}

The second stage includes the formation of a database for selected indicators and regions. The methodology proposed by us is based on the use of the method of interregional comparison, but since the health systems of the subjects of the Russian Federation differ significantly in terms of both the resulting parameters (medical and demographic situation) and influence factors, including the environmental situation, it is necessary to compare not all subjects of the Russian Federation, but to choose regions with similar conditions.

The Republics of Tatarstan and Bashkortostan, Perm, Nizhny Novgorod, Sverdlovsk, Samara and Chelyabinsk regions were chosen as the regions for carrying out the comparative analysis. The regions chosen for comparison were united not only by the geographical location and significant reserves of raw materials (5 out of 7 analyzed regions are part of the PFD and 2 regions are in the UFD, 4 out of 7 regions are included in the Urals economic region), but also by the similar structure of the economy. In all cases, it is based on industrial production, although industry in each region has its own specialization. These regions belong to the old industrial regions, the development of which is determined by the availability of a significant resource base and the determining role of traditional industries in the formation of GRP.

Moreover, all these regions are characterized by a high degree of favorable investment climate, being a part of a group of so-called "supporting" regions, they have a high investment potential and significant internal development resources that allow them to develop fairly steadily without significant support from the federal center, being leading trade-economic partners for each other, part of them are city-millionaires. 
At the third stage, the indicators are completely normalized, as a result of which the range of their possible values is limited to the interval $[0 ; 1]$, where 0 is the worst parameter of the ith criterion and 1 is equal to the best one. The choice of the transformation formula depends on what the given dynamics of the indicator is: if the indicator should tend to increase - formula 1 is used, if to decrease - the formula 2. Then the integral indicator of the ecological component of the regional socio-economic system is calculated (formula 3):

$$
\tilde{\boldsymbol{X}}_{i}=\frac{\boldsymbol{X}_{i}-\boldsymbol{X}_{\min }}{\boldsymbol{X}_{\max }-\boldsymbol{X}_{\min }} \quad(1), \quad \tilde{\boldsymbol{X}}_{i}=\frac{\boldsymbol{X}_{\max }-\boldsymbol{X}_{i}}{\boldsymbol{X}_{\max }-\boldsymbol{X}_{\min }} \quad(2), \quad \overline{\boldsymbol{E}} \overline{\boldsymbol{I}}=\frac{\sum \tilde{\boldsymbol{X}}_{i}}{\boldsymbol{i}}
$$

where $\overline{\boldsymbol{E}} \overline{\boldsymbol{I}}$ is the integral indicator of the ecological component of the regional socioeconomic system; $\tilde{X}_{i}$ is the normalized i-th private indicator, assessing environmental conditions in the region; $\mathrm{i}$ - number of private indicators assessing environmental conditions in the region.

Based on the calculated normalized indicators, we determine the presence and level of (dis)functionality of the ecological subsystem of regional health care system. Under the dysfunctionality of the regional health care system or its separate subsystems (ecological, social, etc.), one should understand a situation in which health needs do not find adequate reflection in the structure and functions of the region's health care system, or the basic functions of this system are not performed to the full extent or are insufficiently effective from the position of the correlation of results and costs [4, c.111].

Author's criteria for assessing the degree of (dis)functionality are presented in Table 2.

Table 2. Criteria for assessing the degree of dysfunction.

\begin{tabular}{|c|c|}
\hline $\begin{array}{c}\text { The value of the } \\
\text { indicator }\end{array}$ & Degree of dysfunction by the indicator (normalized / integral) \\
\hline Less than 0.40 & Maximum \\
\hline $0.40-0.59$ & High \\
\hline $0.60-0.79$ & Average \\
\hline $0.80-0.89$ & Low \\
\hline $0.90-0.99$ & Minimal \\
\hline 1.00 & No dysfunction \\
\hline
\end{tabular}

To assess the environmental determinants of health, Table 3 presents both baseline and normalized indicators that characterize environmental indicators that affect public health state in the estimated regions in 2016.

Table 3. Baseline data for the assessment of environmental conditions and calculation of normalized indicators in 2016 [ 5 , pp. 38, 522, 526, 530 534].

\begin{tabular}{|l|c|c|c|c|c|c|}
\hline \multicolumn{1}{|c|}{ Regions } & $\boldsymbol{X}_{\boldsymbol{6}}$ & $\boldsymbol{X}_{\boldsymbol{7}}$ & $\boldsymbol{X}_{\boldsymbol{8}}$ & $\boldsymbol{X}_{\boldsymbol{9}}$ & $\boldsymbol{X}_{\boldsymbol{1 0}}$ & $\bar{E} \overline{\boldsymbol{I}}$ \\
\hline Perm region & 612.8 & 1359.4 & 1.045 & 1.766 & 605.2 & - \\
\hline Bashkortostan Republic & 1278.6 & 69.6 & 1.056 & 0.991 & 192.8 & - \\
\hline Tatarstan Republic & 1351.8 & 83.7 & 1.005 & 0.981 & 191.5 & - \\
\hline Nizhny Novgorod region & 513.0 & 116.1 & 0.946 & 0.560 & 242.9 & - \\
\hline Samara region & 889.3 & 114.9 & 1.018 & 1.254 & 214.8 & - \\
\hline Sverdlovsk region & 2150.9 & 142.5 & 1.039 & 1.029 & 164.7 & - \\
\hline Chelyabinsk region & 2318.2 & 197.9 & 1.043 & 1.099 & 158.5 & - \\
\hline$\tilde{X}_{i}$ for Perm region & $\mathbf{0 . 0 6}$ & $\mathbf{0 . 0 0}$ & $\mathbf{0 . 1 0}$ & $\mathbf{1 . 0 0}$ & $\mathbf{1 . 0 0}$ & $\mathbf{0 . 4 3}$ \\
\hline$\tilde{X}_{i}$ for Bashkortostan Republic & $\mathbf{0 . 4 2}$ & $\mathbf{1 . 0 0}$ & $\mathbf{0 . 0 0}$ & $\mathbf{0 . 3 6}$ & $\mathbf{0 . 0 8}$ & $\mathbf{0 . 3 7}$ \\
\hline$\tilde{X}_{i}$ for Tatarstan Republic & $\mathbf{0 . 4 6}$ & $\mathbf{0 . 9 9}$ & $\mathbf{0 . 4 6}$ & $\mathbf{0 . 3 5}$ & $\mathbf{0 . 0 7}$ & $\mathbf{0 . 4 7}$ \\
\hline$\tilde{X}_{i}$ for Nizhny Novgorod region & $\mathbf{0 . 0 0}$ & $\mathbf{0 . 9 6}$ & $\mathbf{1 . 0 0}$ & $\mathbf{0 . 0 0}$ & $\mathbf{0 . 1 9}$ & $\mathbf{0 . 4 3}$ \\
\hline
\end{tabular}




\begin{tabular}{|l|c|c|c|c|c|c|}
\hline$\tilde{X}_{i}$ for Samara region & $\mathbf{0 . 2 1}$ & $\mathbf{0 . 9 6}$ & $\mathbf{0 . 3 4}$ & $\mathbf{0 . 5 8}$ & $\mathbf{0 . 1 3}$ & $\mathbf{0 . 4 4}$ \\
\hline$\tilde{X}_{i}$ for Sverdlovsk region & $\mathbf{0 . 9 1}$ & $\mathbf{0 . 9 4}$ & $\mathbf{0 . 1 5}$ & $\mathbf{0 . 3 9}$ & $\mathbf{0 . 0 1}$ & $\mathbf{0 . 4 8}$ \\
\hline$\tilde{X}_{i}$ for Chelyabinsk region & $\mathbf{1 . 0 0}$ & $\mathbf{0 . 9 0}$ & $\mathbf{0 . 1 1}$ & $\mathbf{0 . 4 5}$ & $\mathbf{0 . 0 0}$ & $\mathbf{0 . 4 9}$ \\
\hline
\end{tabular}

According to Table 3, the situation in Perm region is the worst one as regards circulating and consecutively used water, discharge of contaminated sewage into surface water bodies and emissions of pollutants from stationary sources into the atmosphere.

As for the quality of atmospheric air, according to the State report "On the state and protection of the environment in the Russian Federation in 2016", all the regions evaluated were Russian regions where the average annual concentration of one or several pollutants in a number of cities exceeds the maximum permissible concentration (MPC) (there was an excess of MAC for the average annual concentration of harmful substances in the atmosphere in Perm region in 4 cities, in Sverdlovsk region in 5 cities, in Samara and Chelyabinsk regions in 3 cities, in the rest of the regions - in 2 cities). In addition, the Perm region and Chelyabinsk region belong to the subjects of the Russian Federation, in which in some cities the maximum concentration of any substance exceeded 10 MPC [6, p.19-20].

This led to a high level (above average Russian one) of primary incidence of bronchitis (chronic and unspecified) and emphysema associated with air quality among children (0-14 years) in Perm region, to an increase in this indicator in Sverdlovsk and Chelyabinsk regions, to a high incidence of primary morbidity bronchitis and emphysema among adults in the Chelyabinsk and Sverdlovsk regions, as well as in the Republic of Tatarstan [6, p.303].

In 2016 the total amount of atmospheric emissions in Perm region was 610.5 thousand tons of pollutants, or $104 \%$ of the level of 2015 , with a share of motor transport roughly the same as from stationary sources $(49.1 \%)$. The main amount of emissions from stationary sources is accounted for "Gazprom Transgaz Tchaikovsky" Ltd, "LUKOIL-Perm" Ltd, TGK-9 JSC, "LUKOIL-Permnefteorgsintez" Ltd, "Chusovskoy Metallurgical Plant” JSC, etc. $[6$, p. 447].

The discharge of contaminated sewage into water in 2016 in Perm region amounted to 357.8 million kub. $\mathrm{m}$ (or $114.5 \%$ of the 2010 level), of which 88.8 million kub. $\mathrm{m}$ was discharged without any purification (which is $6.6 \%$ more than in 2010). Primary pollutants are the Perm branch of Novogor-Prikamye, Promstoki (Berezniki), TGK-9, a branch of Zakamskaya HES-5 (Krasnokamsk), Bereznikovsky Soda Plant JSC. The water consumption in the circulating and re-sequential water supply systems in 2016 were almost $2 \%$ less than in 2015 and $20 \%$ less than in 2010 [6, p.447].

Despite the fact that Perm region occupies the best position among the estimated regions as regards per capita use of fresh water, the volume of fresh water use in 2016 decreased by approximately $36 \%$ compared to the level of 2010 , incl. by reducing the industrial and drinking (almost 25\%) use of water [6, p. 447], and when ranking subjects of the Russian Federation according to the share of the population living in populated areas, provided with benign and conditionally benign drinking water, in 2016 Perm region takes only 32nd place (Tatarstan Republic - 13, Sverdlovsk region - 19) [7, p. 212].

The Perm region belongs to the subjects of the Russian Federation in which the primary incidence associated with water quality exceeds the Russian average figures by 1.5 times or more and is among the three regions where unsatisfactory drinking water quality forms additional cases of diseases of the digestive system [6, p. 306].

Some positive points of regional development should be noted also. Sverdlovsk region, Bashkortostan Republic, Tatarstan Republic and Chelyabinsk region were among the top ten Russian regions with the largest current environmental expenditures were among the top ten Russian regions with the largest current environmental expenditures in 2016 (however, for Bashkortostan and Tatarstan, the costs may be related to penalties, since 
these two regions were among the three regions of the Russian Federation in terms of the number of violations of legislation identified during the state environmental review). In terms of investments in fixed assets aimed at protecting the environment and rational nature management in 2016, the Republic of Bashkortostan ranked 6th among the subjects of the Russian Federation, the Tatarstan Republic was at the 8th place, Chelyabinsk region - 9th, Perm region occupies 15 th position [6, p. 316, 306].

The grades of the analyzed regions in terms of the level of functioning of the ecological subsystem in dynamics are presented in Table. 4.

Table 4. Dynamics of the ecological component of the socio-economic system of the regions and the ranks of the regions by $\bar{E} \bar{I}$.

\begin{tabular}{|c|c|c|c|c|c|c|c|c|c|c|c|c|c|c|}
\hline \multirow{3}{*}{$\begin{array}{l}\text { Year } \\
2000\end{array}$} & \multicolumn{14}{|c|}{ Regions } \\
\hline & \multicolumn{2}{|c|}{ PermR } & \multicolumn{2}{|c|}{ BashR } & \multicolumn{2}{|c|}{ TatR } & \multicolumn{2}{|c|}{ NNovgR } & \multicolumn{2}{|c|}{ SamaraR } & \multicolumn{2}{|c|}{ SverdlR } & \multicolumn{2}{|c|}{ ChelR } \\
\hline & 0,50 & $1=2$ & 0.44 & 3 & 0.38 & 4 & 0.34 & 5 & 0.29 & 6 & 0.50 & $1=2$ & 0.28 & 7 \\
\hline 2001 & 0.51 & 1 & 0.44 & 3 & 0.40 & 4 & 0.36 & 6 & 0.37 & 5 & 0.50 & 2 & 0.29 & 7 \\
\hline 2002 & 0.46 & 2 & 0.44 & 3 & 0.39 & $4=5$ & 0.39 & $4=5$ & 0.38 & 6 & 0.49 & 1 & 0.29 & 7 \\
\hline 2003 & 0.43 & $1=2$ & 0.42 & 3 & 0.38 & $4-5$ & 0.38 & $4=5$ & 0.37 & 6 & 0.43 & $1=2$ & 0.29 & 7 \\
\hline 2004 & 0.53 & 1 & 0.43 & 2 & 0.36 & 5 & 0.38 & 4 & 0.34 & 6 & 0.42 & 3 & 0.32 & 7 \\
\hline 2005 & 0.55 & 1 & 0.43 & 2 & 0.36 & 5 & 0.38 & 4 & 0.35 & 6 & 0.42 & 3 & 0.31 & 7 \\
\hline 2006 & 0.54 & 1 & 0.44 & 2 & 0.36 & 5 & 0.38 & 4 & 0.35 & 6 & 0.42 & 3 & 0.32 & 7 \\
\hline 2007 & 0.60 & 1 & 0.43 & 2 & 0.39 & $4=5$ & 0.39 & $4=5$ & 0.36 & 6 & 0.42 & 3 & 0.34 & 7 \\
\hline 2008 & 0.54 & 1 & 0.43 & 3 & 0.41 & 4 & 0.39 & 5 & 0.38 & 6 & 0.44 & 2 & 0.26 & 7 \\
\hline 2009 & 0.53 & 1 & 0.43 & 3 & 0.41 & 4 & 0.40 & 5 & 0.38 & 6 & 0.45 & 2 & 0.33 & 7 \\
\hline 2010 & 0.55 & 1 & 0.43 & 3 & 0.40 & 4 & 0.37 & 6 & 0.38 & 5 & 0.50 & 2 & 0.36 & 7 \\
\hline 2011 & 0.48 & 2 & 0.43 & 3 & 0.39 & 4 & 0.37 & $5=6$ & 0.37 & $5=6$ & 0.49 & 1 & 0.34 & 7 \\
\hline 2012 & 0.46 & 1 & 0.43 & 3 & 0.37 & 5 & 0.36 & $6=7$ & 0.38 & 4 & 0.45 & 2 & 0.36 & $6=7$ \\
\hline 2013 & 0.46 & 2 & 0.43 & 3 & 0.39 & 5 & 0.36 & $6=7$ & 0.41 & 4 & 0.49 & 1 & 0.36 & $6=7$ \\
\hline 2014 & 0.47 & $1=2$ & 0.42 & 3 & 0.38 & $4=5$ & 0.35 & $6=7$ & 0.38 & $4=5$ & 0.47 & $1=2$ & 0.35 & $6=7$ \\
\hline 2015 & 0.46 & 2 & 0.43 & 3 & 0.41 & 4 & 0.36 & $5=6$ & 0.36 & $5=6$ & 0.48 & 1 & 0.34 & 7 \\
\hline 2016 & 0.43 & $5=6$ & 0.37 & 7 & 0.47 & 3 & 0.43 & $5=6$ & 0.44 & 4 & 0.48 & 2 & 0.49 & 1 \\
\hline
\end{tabular}

Despite the fact that throughout the analyzed period, the ecological situation in Perm region was characterized by a high level of dysfunctionality, the Perm region along with the Sverdlovsk region took the first lines of the rating (except for 2016), as in the other estimated regions the ecological component of the health saving process was even more dysfunctional.

If we evaluate the dynamics, the Perm region, Bashkortostan Republic and Sverdlovsk region show a deterioration in the environmental situation in comparison with the competitors, the Tatarstan Republic, Nizhny Novgorod, Samara and Chelyabinsk regions show significant improvement (Table 5).

Table 5. The dynamics of the integral indicator of the performance of the function of the ecological subsystem of regional health systems.

\begin{tabular}{|l|c|}
\hline \multicolumn{1}{|c|}{ Regions } & Rate of increase $\bar{E} \bar{I}, \mathbf{\%} \mathbf{2 0 1 6}$ to 2000 \\
\hline Perm region & -14.0 \\
\hline Bashkortostan Republic & -15.9 \\
\hline Tatarstan Republic & +23.7 \\
\hline Nizhny Novgorod region & +26.5 \\
\hline Samara region & +51.7 \\
\hline Sverdlovsk region & -4.0 \\
\hline Chelyabinsk region & +75.0 \\
\hline
\end{tabular}

After estimating the growth rate of the integral indicator of the dysfunctionality of the ecological subsystem of the health care systems of the assessed regions (Table 5), we will 
determine the type of the region by the ratio of the level of dysfunctions of the ecological subsystem of regional health care and its dynamics (Fig. 1).

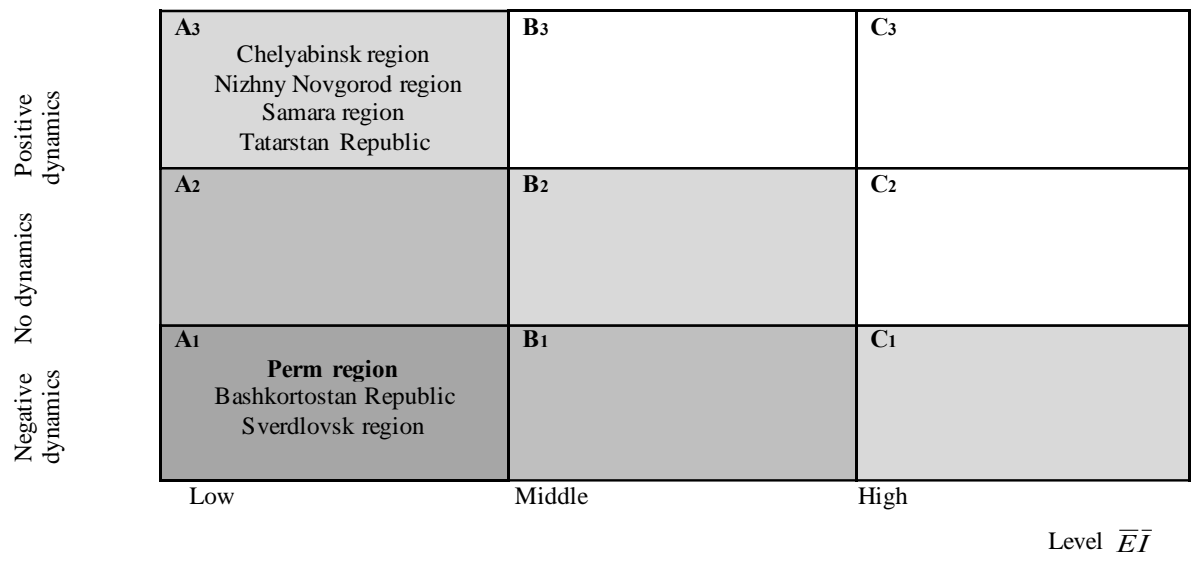

Fig. 1. Typology of regions on the state and dynamics of the functioning of the ecological subsystem of public health care.

The following grouping of regions is proposed:

Group $\mathbf{A}_{1}$ - regions with a high level of environmental dysfunctions in the health space and negative dynamics of the functioning of the ecological component of the regional health system ( $\bar{E} \bar{I} \leq 0,59$; negative dynamics of $\bar{E} \bar{I}$ );

$\mathbf{A}_{\mathbf{2}}$ - regions with a high level of environmental dysfunctions in the field of health preservation and promotion and lack of dynamics of dysfunctionality of the ecological health subsystem ( $\bar{E} \bar{I} \leq 0,59$, zero dynamics of $\bar{E} \bar{I}$ );

$\mathbf{A}_{\mathbf{3}}$ - regions with a high level of dysfunctions of the ecological subsystem of health care, but positive dynamics of the functioning of the ecological subsystem of public health care $(\bar{E} \bar{I} \leq 0,59$, positive dynamics of $\bar{E} \bar{I})$;

$\mathbf{B}_{1}$ - regions with an average level of dysfunctions of the ecological subsystem of health care and negative dynamics of the functioning of the ecological component of the regional health system ( $\bar{E} \bar{I} \in 0,6-0,79$; negative dynamics of $\bar{E} \bar{I}$ );

$\mathbf{B}_{2}$ - regions with an average level of dysfunctions of the ecological subsystem of public health and lack of dynamics of dysfunctions of the ecological subsystem of public health services $(\bar{E} \bar{I} \in 0,6-0,79$, zero dynamics of $\bar{E} \bar{I})$;

$\mathbf{B}_{\mathbf{3}}$ - regions with an average level of dysfunctions of the ecological subsystem of public health and positive dynamics of the functioning of the ecological subsystem of public health ( $\bar{E} \bar{I} \in 0,6-0,79$, positive dynamics of $\bar{E} \bar{I})$;

$\mathbf{C}_{1^{-}}$- regions with a low level of dysfunctions of the ecological subsystem of health care and negative dynamics of the functioning of the ecological component of the regional health care system ( $\bar{E} \bar{I} \in 0,8-1,0$ negative dynamics of $\bar{E} \bar{I}$ );

$\mathbf{C}_{2}$ - regions with a low level of dysfunctions of the ecological health subsystem and its lack of dynamics $(\bar{E} \bar{I} \in 0,8-1,0$ zero dynamics of $\bar{E} \bar{I})$; 
$\mathbf{C}_{\mathbf{3}}$ - regions with a low level of dysfunctions of the ecological subsystem of health care and positive dynamics of its functioning ( $\bar{E} \bar{I} \in 0,8-1,0$ positive dynamics of $\bar{E} \bar{I}$ ).

All the evaluated regions are in the $\mathbf{G}$ group and are characterized by a high level of environmental dysfunctions in the health area, while Perm region demonstrates also the negative dynamics of the functioning of the ecological component of the regional health system (G1 group).

We analyzed the impact of regional institutional factors, including environmental conditions in the region, on the health of the population of the regions, and also assessed the impact of health of residents of selected regions on GRP and HDI. In addition to environmental factors affecting the state of public health, social factors (crime rate, unemployment, housing conditions, etc., 10 indicators in total), health care resources (5 indicators), behavioral factors in the health of the population and employers (12 indicators) [calculated according to: 5, 8], management factors (through assessing the level of implementation of target indicators reflected in regional health programs and / or socioeconomic programs of development). All selected indicators also underwent full normalization, as well as 6 indicators assessing the health status of the inhabitants of the region, for each group of factors, integrated indicators were calculated.

Table 6 presents the results of the regression analysis of the impact of the institutional factors of the region on regional public health (an integral indicator that assesses the medical and demographic situation in the region).

Table 6. Regression models for assessing the impact of integrated indicators (dis) functionality of health care subsystems of the region on the medical and demographic situation in the analyzed regions.

\begin{tabular}{|c|c|c|c|c|}
\hline Region & \multicolumn{4}{|c|}{ Regression equation } \\
\hline & $\mathbf{R}^{2}$ & Normalized $\mathbf{R}^{2}$ & $\mathbf{F}$ & Value of $F$ \\
\hline \multirow[t]{2}{*}{ Perm region } & \multicolumn{4}{|c|}{$\bar{Y}=1,94-1,73 \bar{M}+1,23 \bar{I}-0,88 \bar{E} \bar{I}+1,12 \bar{S} \bar{I}+0,64 \bar{P}-0,38 \bar{E}$} \\
\hline & 0.92 & 0.69 & 3.9 & 0.22 \\
\hline \multirow{2}{*}{$\begin{array}{l}\text { Bashkortostan } \\
\text { Republic }\end{array}$} & \multicolumn{4}{|c|}{$\bar{Y}=-74,5-1,73 \bar{M}+0,99 \bar{I}-38,9 \bar{E} \bar{I}+2,1 \bar{S} \bar{I}-4,0 \bar{P}+1,92 \bar{E}$} \\
\hline & 0.88 & 0.52 & 2.5 & 0.32 \\
\hline \multirow{2}{*}{$\begin{array}{l}\text { Tatarstan } \\
\text { Republic }\end{array}$} & \multicolumn{4}{|c|}{$\bar{Y}=10,0-11,24 \bar{M}+0,6 \bar{I}-0,88 \bar{E} \bar{I}+1,66 \bar{S} \bar{I}-0,48 \bar{P}+0,56 \bar{E}$} \\
\hline & 0.90 & 0.58 & 2.7 & 0.28 \\
\hline \multirow{2}{*}{$\begin{array}{l}\text { Nizhny } \\
\text { Novgorod } \\
\text { region }\end{array}$} & \multicolumn{4}{|c|}{$\bar{Y}=3,21-3,41 \bar{M}+0,48 \bar{I}+3,03 \bar{E} \bar{I}-0,76 \bar{S} \bar{I}-0,74 \bar{P}-0,15 \bar{E}$} \\
\hline & 0.95 & 0.83 & 7.6 & 0.12 \\
\hline \multirow{2}{*}{$\begin{array}{l}\text { Samara } \\
\text { region }\end{array}$} & \multicolumn{4}{|c|}{$\bar{Y}=31,0-29,29 \bar{M}-0,05 \bar{I}-7,96 \bar{E} \bar{I}+1,89 \bar{S} \bar{I}+1,11 \bar{P}-0,09 \bar{E}$} \\
\hline & 0.99 & 0.99 & 1284.1 & 0.02 \\
\hline \multirow{2}{*}{$\begin{array}{l}\text { Sverdlovsk } \\
\text { region }\end{array}$} & \multicolumn{4}{|c|}{$\bar{Y}=-0,56+0,4 \bar{M}-0,27 \bar{I}+0,89 \bar{E} \bar{I}+0,84 \bar{S} \bar{I}+0,54 \bar{P}+0,76 \bar{E}$} \\
\hline & 0.86 & 0.42 & 1.97 & 0.37 \\
\hline \multirow{2}{*}{$\begin{array}{l}\text { Chelyabinsk } \\
\text { region }\end{array}$} & \multicolumn{4}{|c|}{$\bar{Y}=-0,07-1,07 \bar{M}+0,09 \bar{I}+2,09 \bar{E} \bar{I}+1,42 \bar{S} \bar{I}+0,86 \bar{P}-1,13 \bar{E}$} \\
\hline & 0.97 & 0.90 & 12.74 & 0.07 \\
\hline
\end{tabular}

The regression analysis confirmed the existence of a substantial direct connection between the health of the inhabitants of the Perm region and the integral indicators of its resource support, social component $(\bar{I})$, the self-preservation behavior of the inhabitants of the region $(\bar{S} \bar{I})$, and feedback on the integral indicators of the functioning of the ecological 
component of the regional health system $(\bar{P})$ and the behavior of employers in the field of labor protection of workers $(\bar{E})$ and a comprehensive indicator of the effectiveness of health management in the region $(\bar{M})$.

The uncorrected and corrected multiple determination coefficients, which were equal to 0.92 and 0.69 , respectively, and the validity of the multiple regression equation using the Fisher's F-criterion, indicate on the model quality (statistical significance of the determination coefficient and statistical reliability of the regression equation): F calc. (3.9)> F crit. (0.22).

Medical and demographic situation in the Bashkortostan and Tatarstan Republics are influenced positively by social factors and the behavior of employers in the field of labor protection and health preservation.

The state of public health in Nizhny Novgorod and Sverdlovsk regions is largely due to environmental factors.

A significant direct relationship between the medical and demographic situation in the Samara region and the level of performance of the functions of the social subsystem and the self-preserving behavior of the inhabitants of the region was revealed.

The health status of residents of the Chelyabinsk region is positively influenced by environmental and social factors, as well as the population's behavior in the field of health preservation.

Next, a regression model was constructed to assess the impact of the medical and demographic performance of the healthcare system of the Perm region $(\bar{Y})$ on the regional HDI. The equation of regression has the form:

ИРЧП $=0,57+0,29 \bar{Y}$ and confirms the existence of a significant positive relationship between the HDI of the Perm region and the state of public health of its inhabitants $\left(\mathrm{R}^{2}=\right.$ 0.84 , normalized $\mathrm{R}^{2}=0.82$, F calculated $(37.67)>\mathrm{F}$ critical $(0,0005)$ ).

The regression model that assesses the impact of the integral indicator of the medical and demographic performance of the health care system of the Perm region $(\bar{Y})$ on the GRP per capita indicator of Perm region also shows a significant positive relationship between the state of public health in the region and the GRP. The regression equation takes the form: $G R P=96088,12+421820,8 Y \quad, \mathrm{R}^{2}=0.79$, normalized $\mathrm{R}^{2}=0.76, F$ calc. 26.26> F crit. (0.001).

Environmental problems pose a threat to the demographic security of the regions, so it is necessary to take measures both at the federal and regional levels to address them. To such measures, researchers refer to the growth of investments in the green economy, incl. and public investment, the formation of a regional economy that will stimulate the sustainable development of the region, take into account the territorial specificity of nature management, reduce the negative anthropogenic impact on the local ecosystem, and use environmental protection measures for the inhabitants of the region [9, p.109].

\section{References}

1. N. Reus, Vestnik MSTU, 14, 2 (2011)

2. N. Piskulova, Bulletin of the Moscow State Institute of International Relations, 6 (2010)

3. Enerdata, Global statistical yearbook for energy 2018: $\mathrm{CO}_{2}$ intensity (https://yearbook. enerdata.net/co2-fuel-combustion/world-CO2-intensity.html, 2018)

4. A. Pepelyaeva, Bulletin of Prikamsky Social Institute, 76, 1 (2017)

5. Rosstat, Regions of Russia: socio-economic indicators (Rosstat, Moscow, 2017) 
6. The State report "On the state and on the protection of the environment of the Russian Federation in 2016" (Ministry of Natural Resources of Russia; NIA-Nature, Moscow, 2017)

7. On the state of sanitary and epidemiological welfare of the population in the Russian Federation in 2016: State report (Federal Service for Supervision of Consumer Rights Protection and Human Welfare, Moscow, 2017)

8. Supplement to the collection "Health care in Russia: 2017" (Rosstat, Moscow, 2017)

9. G. Kudinova, Bulletin of Volgograd State University. Series 3: Economy. Ecology, 4 (2014) 